\title{
Assessment of Decomposition Studies Indicates Need for Standardized and Repeatable Research Methods in Forensic Entomology
} Jeffery K Tomberlin ${ }^{1 *}$, Jason H Byrd ${ }^{2}$, John R Wallace ${ }^{3}$ and M Eric Benbow ${ }^{4}$

${ }^{1}$ Department of Entomology, Texas A\&M University, College Station, Texas, USA

${ }^{2}$ University of Florida College of Medicine, Department of Pathology, Immunology and Laboratory Medicine, Gainesville, Florida, USA

${ }^{3}$ Department of Biology, Millersville University, Millersville, Pennsylvania, USA

${ }^{4}$ Department of Biology, University of Dayton, Dayton, Ohio, USA

\begin{abstract}
The National Research Council (NRC) released a report in 2009 discussing the "science" used in forensics. Specifically, the report outlined concerns regarding the state of the forensic sciences and what was needed to raise the level of rigor and reliability of these fields in a court of law. In response to this NRC document, the present paper examined several parameters used in decomposition studies that have implications for forensic entomology. Specifically, this analysis was conducted to determine the degree of repeatability in methods across studies as related to general conclusions drawn in court, entomology and forensic investigations. Forensic entomologists primarily analyze insect evidence recovered from decomposing remains to estimate a portion of the Period of Insect Activity (PIA), which encompasses the time of colonization, to infer a minimum Postmortem Interval (PMI). One method utilized by entomologists relies on succession data from published studies to generate estimates of the minimum PMI of a decedent. For this article, approximately 75 publications on arthropod succession on vertebrate carrion were reviewed for 13 criteria that are known to play instrumental roles in governing this process: 1) animal model, 2) time of actual death, 3) euthanasia method, 4) storage method, 5) storage time, 6) time of removal from storage to placement in the field, 7) time of day remains placed in the field, 8) catalog of arthropods associated with the remains over time 9) time of initial insect contact, 10) time of initial colonization (i.e., arthropod offspring located on the remains), 11) study site, 12) number of replicate carcasses and 13) months and season of study. These criteria were selected as they can directly impact arthropod colonization and succession patterns on vertebrate carrion and are easily recorded. Data indicated that such information is highly fragmented, and that key criteria necessary to repeat studies (a core principle of the scientific method) are often lacking in the published literature. As an example, among the studies included in this analysis, we could not find significant associations between arthropod taxa richness and carcass model or carcass size. In the case of carcass size, island biogeography theory predicts that larger areas/resources will hold higher diversity. We suspect that the high degree of reporting variability in taxonomic resolution and taxa-specific study focus precluded such relationships that have been reported for other disciplines of biology. Consequently, we suggest that, to date, because of these issues there has not been a comprehensive analysis (e.g., meta-analysis) to provide general inference of arthropod succession patterns on carrion to predict a minimum PMI. In order to begin standardizing such studies, we suggest that future research endeavors examining arthropod succession on carrion record detailed data for all of the suggested criteria. Doing so can result in data amassed over time for use in comprehensive and strong meta-analyses. Such results could allow for greater appreciation of variation associated with arthropod succession on carrion.
\end{abstract}

\section{Introduction}

The postmortem interval (PMI) encompasses the period of time from when an individual died to when the remains of that individual are discovered, or simply put, how long someone has been dead [1]. The correct determination of the time of death is an important goal in forensic medicine as well as any death scene investigation. Forensic entomologists are often asked to estimate the PMI of decomposing human, and at times animal, remains [2-5]. In some cases, this arthropod-based estimation has been the most dependable when dealing with remains decomposing for weeks or longer [6]. PMI estimates by forensic entomologists have primarily been based on arthropod development and/or succession models on carrion. However, precision and accuracy in such estimates may be limited. This limitation may be due to several factors including; 1) a lack of "known" times of death for individuals from past casework; 2) a paucity of validation studies for development data of arthropods of forensic importance, and; 3) a need for clarification of the abiotic and biotic variables that determine when colonization occurs with respect to the actual time of death - a semantic argument that influences the entomologist's implied inference of a PMI estimation. In many cases, estimates of time of arthropod colonization are more in line with a minimum PMI.
For many years, forensic entomologists often communicated their ability to determine the actual PMI of a decedent [2]. Recent publications have revisited this concept and determined that estimating a PMI based on calculating the time of arthropod colonization of remains [7], also termed the post-colonization interval [8,9], can be accurate $[10,11]$. These estimates represent the period of time from colonization of the remains by arthropods to the discovery of the remains. In most cases, this period more readily translates into a range

*Corresponding author: Jeffery K. Tomberlin, 2475 TAMU, Department of Entomology, Texas A\&M University, College Station, Texas 77843, USA, Tel : 979.845.9718; E-mail: jktomberlin@ag.tamu.edu

Received February 21, 2012; Accepted April 12, 2012; Published April 14, 2012

Citation: Tomberlin JK, Byrd JH, Wallace JR, Benbow ME (2012) Assessment of Decomposition Studies Indicates Need for Standardized and Repeatable Research Methods in Forensic Entomology. J Forensic Res 3:147. doi:10.4172/21577145.1000147

Copyright: (c) 2012 Tomberlin JK, et al. This is an open-access article distributed under the terms of the Creative Commons Attribution License, which permits unrestricted use, distribution, and reproduction in any medium, provided the original author and source are credited. 
encompassing the minimum PMI. However, we recognize that there are instances when this range might include the actual time since death or the implied PMI or even longer in cases of myiasis. We note here that colonization date often does not necessarily agree with the date of death in many investigations.

Entomological life history data used to explain delays in colonization have not been studied for all forensically relevant species. In most instances, existing published information on factors attributing to the variation associated with colonization and succession patterns of arthropods on human (or vertebrate model) remains tends to be qualitative, limited in scope, or anecdotal. Consequently, these explanations offer little insight towards the precision or accuracy of opinions offered regarding insect behavior (specifically Calliphoridae: blow flies) and delayed colonization on human remains.

We recommend the use of standardized protocols in research examining arthropod succession on carrion because it is important for understanding the variation associated with making PMI estimates in criminal investigations reliant on entomological evidence. For this paper, we reviewed a representative portion of the forensic entomology literature to provide a clearer picture of the often obscure, but inherent, variability in parameters recorded across studies. Our goal was to assess the types of data and parameters reported from a representative range of papers directly related to forensic entomology using a common searchable database; an approach often used for meta-analyses or attempts to make general inferences in a discipline from readily accessible literature. It was not our intention to provide a comprehensive statistical assessment of all papers related to forensic entomology, as there will always be omissions with grey literature and studies published in obscure or highly regional journals that are not broadly distributed. Our second goal was to use this set of papers to assess and describe the variability in data and methods reporting that affects the ability for making broader inferences that can be applied and defended in the discipline of forensic entomology. Based on these results, we propose a unified standard operating procedure that would allow for a more statistically rigorous analysis of these data within and across studies as they relate to understanding variability associated with arthropod succession and its use in PMI estimates. If implemented, data accumulated across studies should lead to a better understanding of the decomposition process, arthropod succession, and improve the accuracy of PMI estimates with these data. It is our intention that these suggestions will lead to PMI estimates based on entomological evidence that meets the criteria for admission of scientific evidence and related testimony (i.e., Daubert standard) [8,9] that addresses the 2009 NRC report [12].

\section{Standard Operating Procedure for Succession Research}

From published papers, we evaluated 13 criteria important for repeatability of a study on arthropod succession on carrion. These criteria were: 1) animal model, 2) time of actual death, 3) euthanasia method, 4) storage method, 5) storage time, 6) time of removal from storage to placement in the field, 7) time of day remains placed in the field, 8) catalog of arthropods associated with the remains over time 9) time of initial insect contact, 10) time of initial colonization (i.e. arthropod offspring located on the remains), 11) study site, 12) number of carcass replicates, and 13) the months and season of study (Figure 1). Eleven criteria are presented in Figure 1. The remaining two criteria, animal model and number of replicates, were not included in Figure 1 as all papers provided some relevant information.
In order to conduct this survey, the terms "forensic entomology" and "succession" were used as key words in a literature search in the Commonwealth Agricultural Bureau database as this database is a source for the applied sciences. Approximately 75 articles representing the breadth of peer-reviewed published research associated with carrion and human decomposition spanning from the 1980s to the present were reviewed for the above 13 criteria. Articles ranging from the 1950s to the 1980s were added through a search of our files in order to compensate for the potential bias of contemporary search engines. This survey of the literature was not meant to be an exhaustive assessment of carrion decomposition relevant to forensic entomology that has been published. Rather, our goal was to evaluate a portion of the literature that used both 'forensic entomology' and 'succession' within the content of the published paper to represent the trends in research that had forensic entomological relevance. The survey was meant to identify and address key aspects of data that are necessary to perform more robust statistical analyses (e.g., meta-analysis) necessary to generate larger generalizations about the biological, ecological and evolutionary underpinnings of forensic entomology. Summaries of the studies are presented in figure form in order to avoid identifying authors and to more appropriately highlight the criterion of interest.

\section{Statistical Evaluation}

In order to evaluate relationships of invertebrate taxa richness with carcass type, size class and mass, we analyzed taxa richness from 40 published papers where the arthropod taxa lists were given for vertebrate carcass decomposition experiments. Using these taxa lists and the published paper as the replicate, we employed non-parametric Kruskal-Wallis tests to statistically evaluate taxa richness differences among carcass types (e.g., swine, bear, and rat) and size classes (e.g., groupings by $10 \mathrm{~kg}$ intervals) (Figure 2). Linear regression also was used to test for the relationship of taxa richness with mean carcass mass (Figure 3). For the remaining criteria and potential relationships among criteria, there was inadequate information reported from the literature, and thus, no statistical analyses were performed.

\section{Animal Models}

A large diversity of animal species has been used in decomposition studies (Figure 4). These animal models included, but were not limited to, chickens, Gallus gallus domesticus (Linnaeus) [13], lab mice, Mus

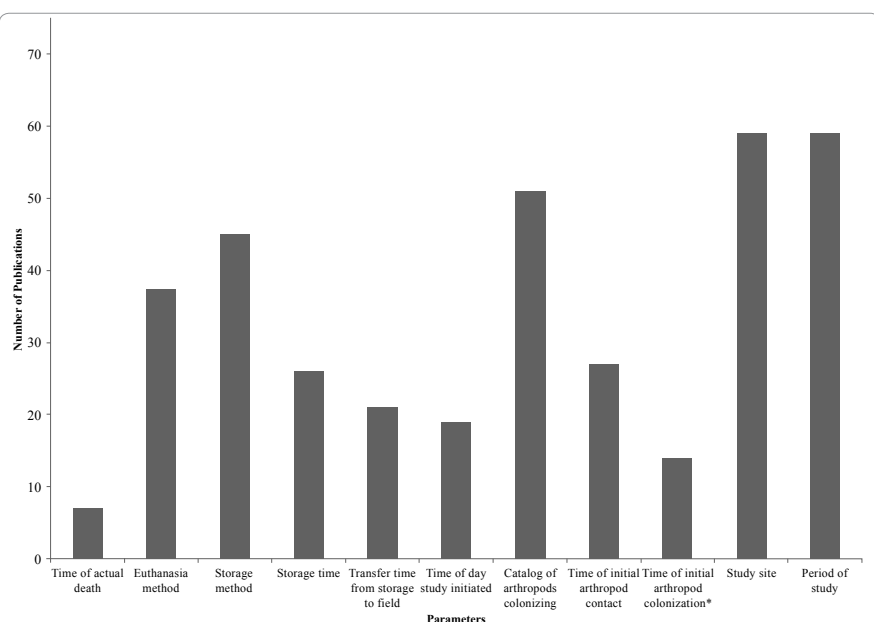

Figure 1: A summary of articles reviewed and partitioned into categories as defined in this publication. 
musculus Linnaeus [14], sheep, Ovis aries Linnaeus [15], domesticated cats, Felis catus (Linnaeus) [16], and monkeys, for instance Cercopithecoidea sp and Presbytis cristata (Horsfield) [17]. However, previous investigators have primarily used the domestic pig, Sus scrofa, as a research model for forensic entomology [18-25] which has been demonstrated in a limited sense to be a suitable analog for human subjects in forensic entomology as the arthropod faunal succession is similar between both species [26]. Additional research comparing human to pig decomposition is still needed as the previous study cited is from a single location in Tennessee and only contained a single human replicate. Other studies, such as Hewadikaram and Goff [27], have suggested that the taxa recovered from carcasses of varying sizes do not differ [27]. However, several studies do indicate that documented arthropod taxa vary depending on the species of animal used in the study. Published studies on rabbit [28-32] and rat carrion [33-36] show a general trend of less arthropod diversity than on pig carcasses. This conflicted finding could be compounded by carcass size [37], amount of hair on the body, and insufficient published data did not allow for a direct comparison between rats, rabbits, and fetal pigs or adult pig carcasses. Preliminary decomposition studies have been conducted on wildlife carcasses (black bear, Euarctos americannus Gray; white-tailed deer Odocoileus virginianus Zimmerman; American alligator, Alligator mississippiensis Daudin; and domestic pig) and determined that alligator carcasses hosted less diversity than either of the three mammal species [38]. From such work, it appears evident that at least some arthropods may exhibit a carrion preference. Consequently, future research studies should record information such as animal species, size, and sex. We note two explanations for such variation in diversity. Such preferences may exist because of developmental differences as noted by Clark et al. [39] in which Lucilia sericata (Meigen), (Diptera: Calliphoridae) larvae

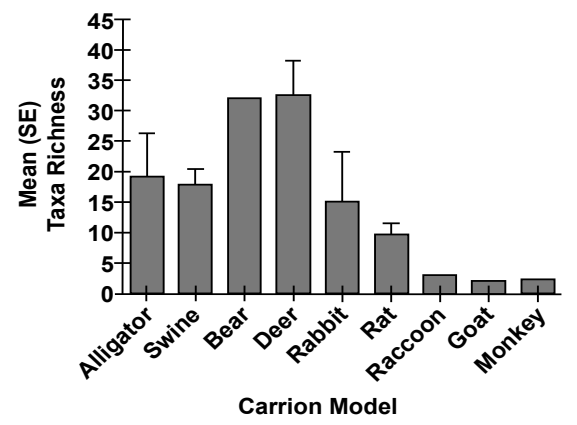

Figure 2: Mean (SE) invertebrate taxa richness by carcass type reported from the papers reviewed and given in Figure 1 that reported carcass type. The mean and SE were generated with paper as the replicate.

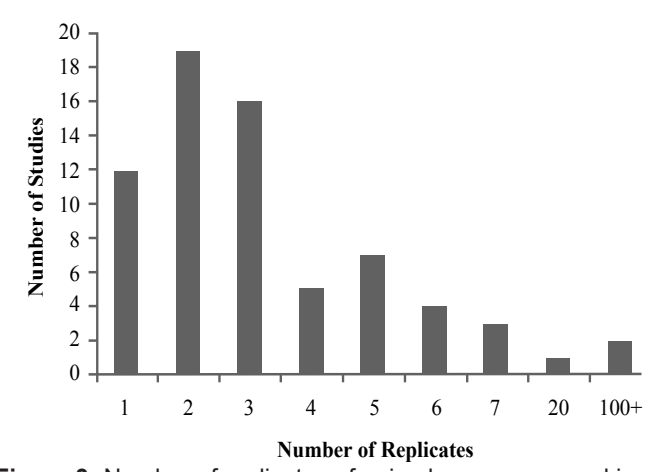

Figure 3: Number of replicates of animal carcasses used in studies.

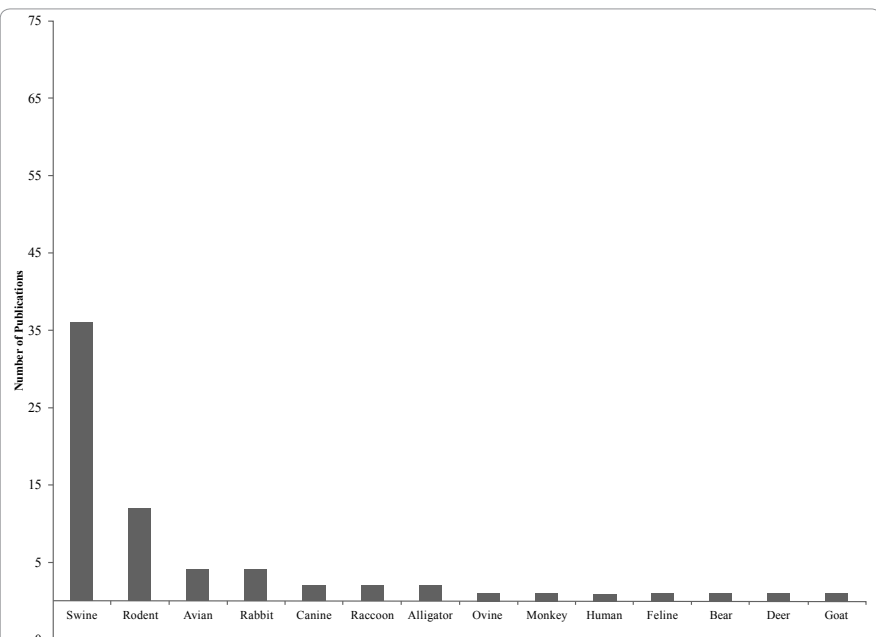

Figure 4: Summary of animal models used in past arthropod succession studies aimed at use in forensic entomology.

grew much faster on pork than beef. An alternative explanation for such preferences may be due to different desiccation rates for exposed tissue, which may not be relevant to decomposition on carrion [40]. In many instances, significant differences in taxa and rate of biomass removal did exist between varying habitats [41-44]. Carcass placement studies have compared placement on ground [45], hanging [42], burned carrion [41], and sun vs. shade exposure [46], and noted differences in the arthropod colonization patterns and carcass decomposition rate.

\section{Time of Death}

The time of death offered by investigators is based on quantitative, as well as qualitative data obtained through the examination of the remains, recovery site, as well as information obtained by others involved in the investigation. The term "time of death" and PMI are often used inter-changeably in the literature. However, it is imperative that researchers not mix up these terms as they have different meanings.

We suggest that caution should be used when using these terms to describe the data collected during arthropod succession studies. Of the 75 papers reviewed, the actual time of death (Figure 5) was quantitatively (i.e., an actual time) recorded in only three studies $[20,23,47]$ and qualitatively (i.e., a general time frame such as morning or evening) in another three [48-50]. These studies represent $<10 \%$ of the studies reviewed. Therefore, relating time of colonization to the actual time of death by the authors or those using these data is not recommended. In order to gain a better, and statistically relevant, predictive ability, we recommend that researchers record the specific time of death as such information could lead to a better understanding of the variation between death and actual colonization of the remains.

\section{Storage Method, Storage Time, and Transition Period from Storage to Field for Animal Remains}

Storage of animals used in decomposition studies was highly variable (Figure 6). Methods varied from placement of the remains in a freezer $[41,51,52]$ to nothing at all [53-55]. In many instances, locating a suitable number of animals (Figure 7) to meet replication requirements for a strong experimental design was difficult. Typically, researchers are often required to purchase and store animals until the targeted number of specimens has been reached to conduct an experiment. In the literature examined, this hurdle was best exemplified 
by those individuals examining arthropod succession on endangered or protected animals $[49,56]$.

In many instances, the method of euthanasia (Figure 8) was highly variable. Many data, such as the methods employed to store the animals (Figure 6), time stored (Figure 9), or the time from the removal of the remains from the storage unit to their placement in the field (Figure 10) were rarely recorded. We provide several examples to

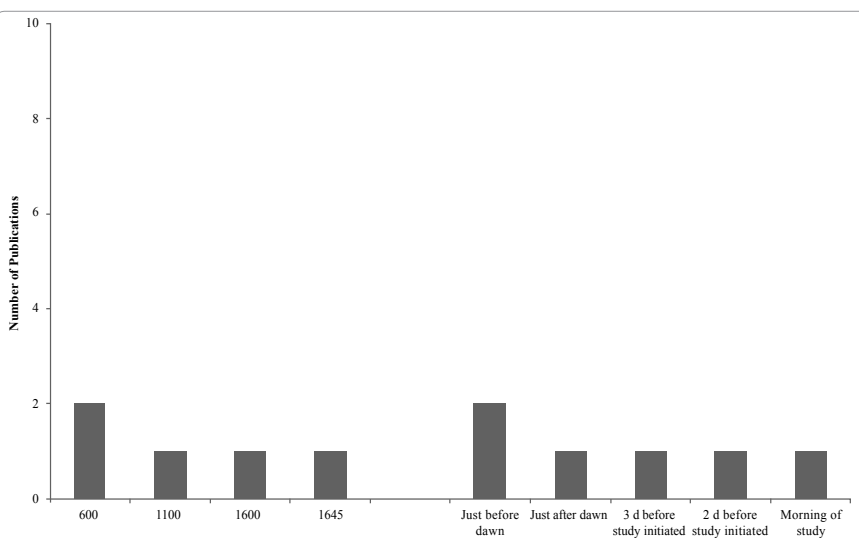

Figure 5: Summary of arthropod succession studies recording quantitative and qualitative measure of actual time of death of animal models used.

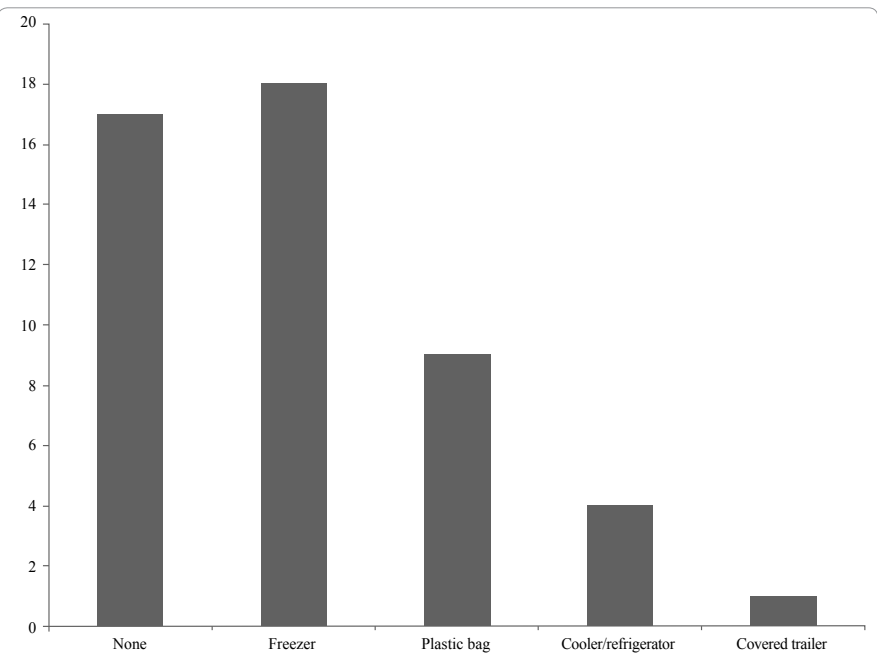

Figure 6: Summary of storage methods used in past arthropod succession studies aimed at use in forensic entomology.

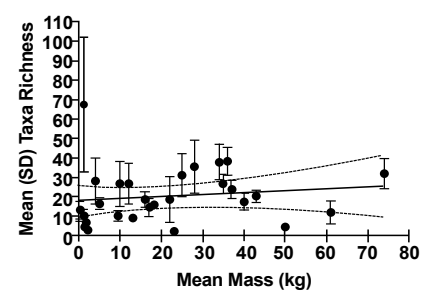

Figure 7: Mean (SD) invertebrate taxa richness by measured carcass mass reported from the papers reviewed and given in Figure 1 that reported carcass mass. The mean and SD were generated with paper as the replicate. A linear regression was fitted to these data, but there was not a significant relationship ( $F$ $=0.54, \mathrm{df}=1,27, \mathrm{p}=0.471$ ).

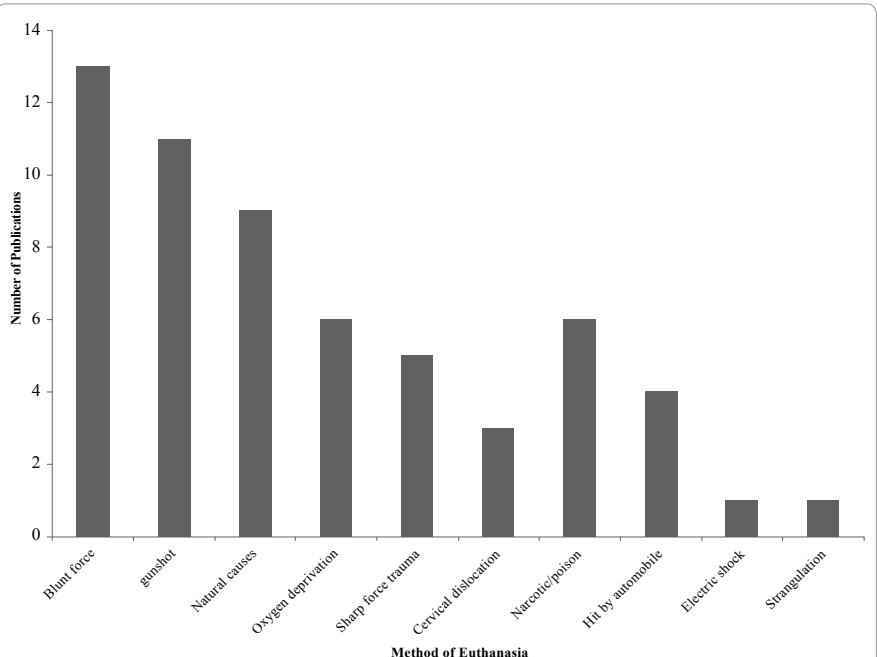

Figure 8: Summary of euthanasia method used in past arthropod succession studies aimed at use in forensic entomology.

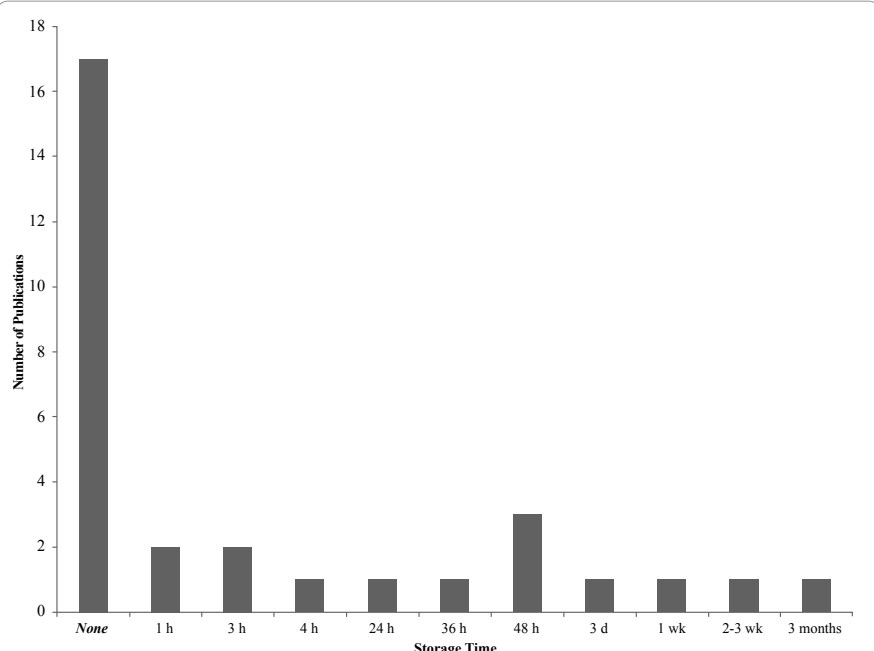

Figure 9: Summary of storage time recorded for past arthropod succession studies aimed at use in forensic entomology.

illustrate this position. Tomberlin and Adler [34] did not freeze their euthanized animals but placed them in plastic bags and transported them to the field; requiring additional time prior to commencing with the experiment. Van Laerhoven and Anderson [57] used fresh carcasses as well, but also experienced a delay of five to eight hours from death to placement in the field. Schoenly et al. [26] utilized a single human and multiple porcine corpses in their study and indicated a minimum of 48 $\mathrm{h}$ storage at $4^{\circ} \mathrm{C}$. Tessmer et al. [58] used longhorn chickens euthanized with $\mathrm{CO}_{2}$ and stored for two days, and Michaud and Moreau [24] used freshly euthanized pig carcasses that were double bagged. Both studies experienced a two hour delay from death of their animals to their placement in the field, while Patrican and Vaidyanathan [59] utilized $\mathrm{CO}_{2}$ and sodium pentobarbital to euthanize rats and needed one to four hours post euthanization to transfer them to the field. Micozzi [60] used Wistar rats euthanized with cervical dislocation and stored them in a freezer for four weeks, while Reed [61] used canines euthanized with strychnine and freshly placed in the field. In both cases, the authors needed eight to nine hours respectively to move their animals to the field. In contrast to these shorter time intervals, 
Tullis and Goff [62] used pig carcasses euthanized with undisclosed methods and stored in a freezer. The remains were allowed to thaw for $16 \mathrm{~h}$ prior to moving them to the field. Archer and Elgar [63] used fresh stillborn piglets and in other instances used piglets that had been stored in a freezer for an undisclosed period $[63,64]$. In all of these cases, if the authors used arthropods to estimate a PMI they would have been grossly inaccurate in such estimates because of the amount of time in storage. An analogy is if a frozen mastodon was thawed and exposed to carrion arthropods, the PIA would accurately reflect how long insects had been present on the remains, but if a PMI would be estimated using the same insect evidence, it would be grossly inaccurate by potentially thousands of years.

Previous studies that recorded amount of time in storage and time from removal from storage, or euthanization, to the field (Figures $7-10)$ represented approximately $15 \%$ of the total studies examined. Consequently, there is a need for more standardized methodologies relative to storage method, time and transition periods from lab to field in order to allow for greater accountability of the variation associated with actual time of death, placement in the field, and when arthropod colonization takes place. Such data should allow forensic entomologists to conduct more detailed meta-analyses of arthropod succession patterns leading to a greater understanding of the variability in the time from death to colonization. However, we recognize that the initiation of some studies $[26,38]$ has revolved around the availability of remains and absence or limited proper storage facilities and, under these circumstances, consistency in storage method and initiation of a study will vary. With future research, by simply recording this information a better understanding of the effects of storage on the decomposition and arthropod succession process as well as the parameters guiding the application of these data in investigations may be possible.

Based on the review of these publications, we realize that the actual time of death as it relates to time the remains spend in storage prior to placement in the field can vary greatly depending on the study. For example, Watson and Carlton [38] used a single black bear that had been struck and killed by an automobile the night prior to the initiation of their study. Initial arthropod contact on the bear carcass occurred 15 min after placement of the carcass in the field the next day; however, actual colonization was not noted until day two of the study. With the Watson and Carlton [38] study, time of death was qualitatively recorded (i.e. night before study) as well as colonization (day two of study). The purpose of reviewing this publication was to demonstrate the need for more quantitative approaches (i.e. actual times need to be recorded) in forensic entomology research.

\section{Time of Day Study Initiated}

Sixteen of the 75 reviewed studies indicated the time when the remains were placed in the field (Figure 11). Times were not consistent and ranged from 0600 [20] until $2200 \mathrm{~h}$ [65]. In contrast, some provided qualitative descriptions of the initiation time. For examples, Waston et al. [38] placed their carcasses in the field just before dawn, while Schoenly et al. [26] placed their carcasses in the field the evening before midnight.

The time of day the body is exposed to arthropod activity can result in differences in species abundance and type attracted to the remains [4].During the summer months in Florida, Chrysomya megacephala (Fabricius) (Diptera: Calliphoridae) is typically the first blow fly species to arrive at decomposing remains in the early morning hours

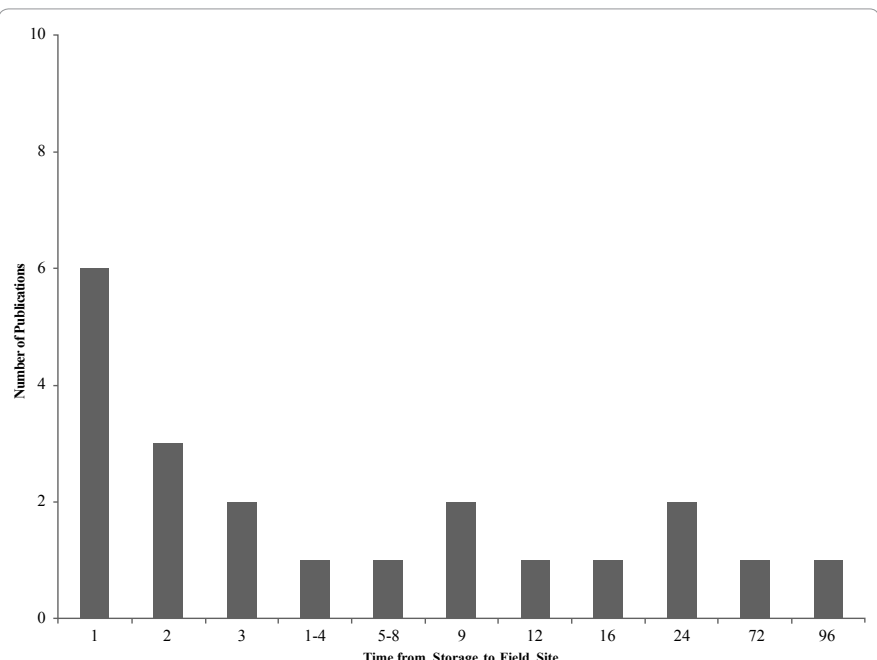

Figure 10: Summary of transfer time from storage to the field recorded for past arthropod succession studies aimed at use in forensic entomology.

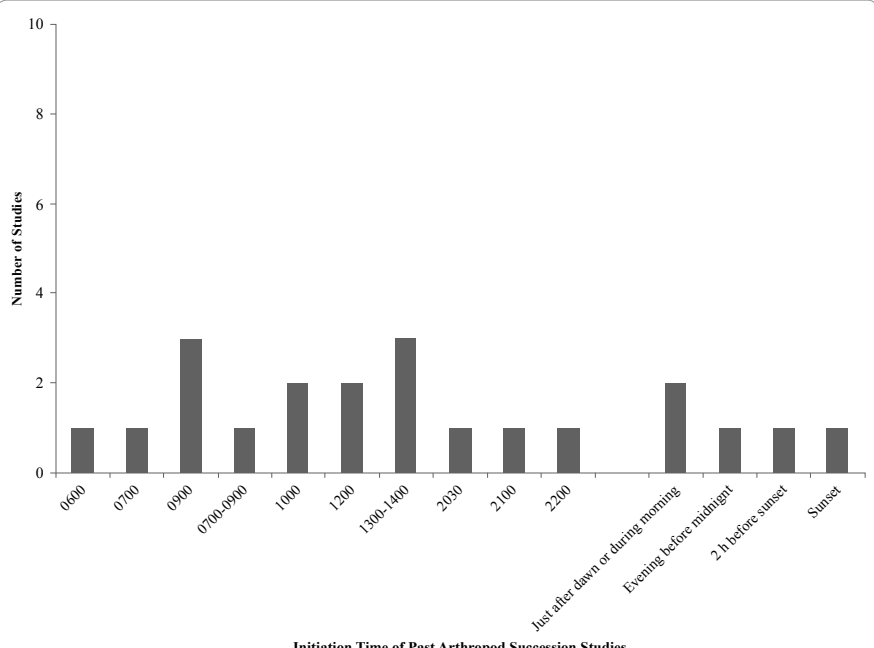

Figure 11: Summary of the initiation time recorded for past arthropod succession studies aimed at use in forensic entomology.

and is often the last to depart carcasses in the evening, sometimes well after sunset (Byrd, pers. observation). Because time of day influences arthropod activity and colonization patterns $[66,67]$, it can be expected that succession patterns would be influenced by the primary species that colonize the remains [68]. Initial colonization by one blow fly species could result in a distinct succession pattern than that generated for another species. For example, Phormia regina (Meigen) and Chrysomya rufifacies Macquart (Diptera: Calliphoridae) are suspected by some to be delayed colonizers, while $L$. sericata is suspected to be an early colonizer [69]. However, the time to colonization can vary depending on the presence of larvae from other blow fly species on a carcass. The presence of $L$. sericata offspring on a carcass decreases the time to colonization by $P$. regina [69]. The same may be true for $C$. rufifacies with time to colonization being dependent on the presence/ absence of Cochliomyia macellaria (Fabricius) (Diptera: Calliphoridae) which is a prey item for this species [70-72]. These assumptions are currently under debate because it is not for certain that these events occur and if such information should be taken into account when estimating the PIA [69]. 
The periodicity of arthropod activity certainly has implications to forensic entomology. For instance, the possibility of nocturnal oviposition has been shown to have profound implications on the extrapolation of the post-colonization interval to estimate the PMI. One of the first studies conducted on nocturnal oviposition by blow flies undoubtedly confirmed that oviposition by L. sericata can occur in dark places during the day, and even during night [65]. Blow fly oviposition occurred on one of six replicate swine carcasses almost two hours after sunset, under heavy cloud cover and during the rain in a forested habitat surrounded by agricultural fields in southwest Ohio (ME Benbow, personal observation). Earlier studies demonstrated that nocturnal oviposition may be possible and that some flies may be facultative, not obligate heliophiles. Greenberg [65] placed bait on the ground under bushes that allowed for the possibility that flies, already at roost on the bushes, to simply walk to the bait without having to take flight. However, in Greenberg [73], street lights might have provided enough light to allow nocturnal colonization to occur. The question of flies laying eggs on a body after dark having been attracted from a distance requiring flight has yet to be definitively answered. For example, in one study, field experiments conducted by Singh and Bharti [74], demonstrated that Calliphora vicina Robineau-Desvoidy (Diptera: Calliphoridae), C. megacephala, and C. rufifacies would oviposit during the night (light intensity $0.6-0.8 \mathrm{~lx}$ ). In a second case, a study by Baldridge et al. [75] showed that necrophilous flies were present on the bait up to $50 \mathrm{~min}$ post-sunset, and activity did not resume until after $0600 \mathrm{~h}$ the following day. This study found that nocturnal oviposition did not occur except in one instance within 20 min post-sunset. Of great interest to forensic entomologists are the published studies $[25,76]$ which included a field component and an indoor study as they allowed for field research to be validated under controlled conditions. These two studies concluded that nocturnal oviposition did not occur under field conditions; however, nocturnal oviposition by $L$. sericata did occur indoors under complete darkness in two of the six trials. These studies supported the original conclusion of Greenberg [65] that oviposition during darkness may occur when, in the Greenberg [73] case, bait is close enough to gravid females not requiring them to take flight to reach the bait source. Another study [77] indicated that instances of nocturnal oviposition did not alter entomologically-based estimations of the post-colonization interval because any such activity would be delayed and result in limited numbers of larvae. Another recent study [25] found that flies did not oviposit under nocturnal conditions in the field. This study also found that oviposition did not occur under complete darkness in a laboratory setting for bait placed on the ground or hanging. This was in contrast to the positive findings of the 2008 study by Amendt [76]. An interesting component of the Zurawski [25] study was that adult flies launched into the air under complete darkness in a laboratory did not fly. Clearly, the limited nocturnal oviposition studies that do exist in the literature are contradictory, and forensic entomologists must take this lack of congruity into account when evaluating this possibility in an estimation of the PMI.

\section{Time of Initial Arthropod Contact}

Tomberlin et al. [9] have defined the time from death to initial arthropod contact as the exposure phase in the decomposition process. While in the past this phase (i.e., time from death to initial arthropod contact) might seem trivial in terms of time, events occurring during this period may be critical for truly estimating the minimum PMI. In some instances where a death occurs at the site in question, this phase is essential for estimating the actual time of death. Of the studies reviewed, $33 \%$ provided information regarding initial arthropod contact with the remains (Figure 12). In most cases, these publications focused on the arrival of blow flies. With this in mind, it should be noted that the time of initial arthropod contact can vary depending on the arthropod being studied. Even with blow flies, their arrival to carrion remains can vary from seconds [78], to minutes [27], or days [79]. Unfortunately, at this time, a true appreciation of the variation surrounding arrival patterns and the regulating variables is limited in the literature.

In many cases, remains are discovered either prior to colonization or well after the majority of the soft tissue has been removed by arthropods competing for these resources. In the latter case, abiotic factors, such as temperature, can shift from conditions suitable for arthropod activity to unsuitable. This shift can be arthropod-specific with the temperature gradient being partitioned into various ranges where only specific arthropods are active. Consequently, arthropods that arrive during one temperature range may be killed prior to oviposition when the temperature shifts, and their remains left on the decomposing resource. Understanding the delay from the moment of death to arrival of arthropods, such as in the case previously described, could become essential for estimating a minimum time of exposure or death for the individual in question, and the dead arthropods located on the remains might be the only evidence harboring this information.

\section{Time of Initial Colonization}

A key component in estimating a minimum PMI is being able to estimate the elapsed time from death to colonization. While this time interval would seem obvious, it has not been a point of emphasis in past decomposition studies. Approximately $20 \%$ of the studies reviewed recorded the time this event occurred (Figure 13). However, only a few recorded the actual, or a retrievable estimate, of time that the studied was initiated $[23,25,38,48,65]$. Consequently, the context of the significance of this event cannot be translated and forces researchers to rely on anecdotal information for interpreting decomposition

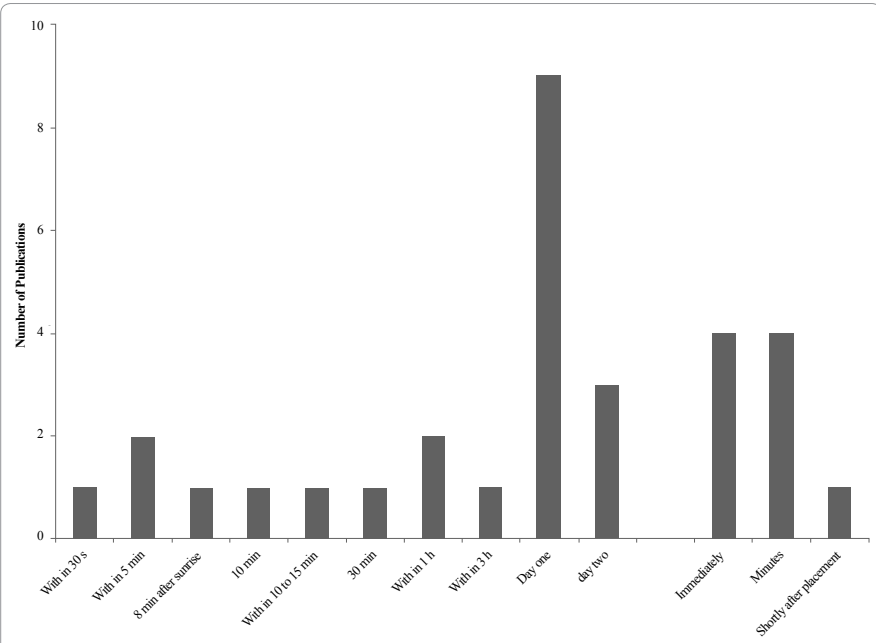

Figure 12: Summary of time of initial arthropod contact with carrion after placement in the field recorded for past arthropod succession studies aimed at use in forensic entomology. 
related events. Such an approach might prove difficult for forensic entomologists attempting to meet the Daubert standard $[8,9]$ and NRC report [12].

\section{Species Diversity}

Depending on the study and the arthropod group targeted, 96\% of the studies recorded detailed information [80] related to adult and immature arthropods arriving and colonizing the remains. For many of these studies, blow flies were the primary focus of the study. However, studies cataloging as much diversity associated with arthropod faunal succession have been conducted. Payne [51,81-83] amassed the most comprehensive collection of arthropods associated with decaying remains. Payne's research demonstrated the diversity of community assemblages that occurred on remains and that there were many opportunities available for research on targeted groups, such as beetles [84], parasitoids [85], and acarids [86].

\section{Study Sites}

Arthropod succession studies are limited to specific regions of the world. Based on a literature review in 2004 [87], researchers from 22 countries conducted succession studies (Figure 14). The six most active

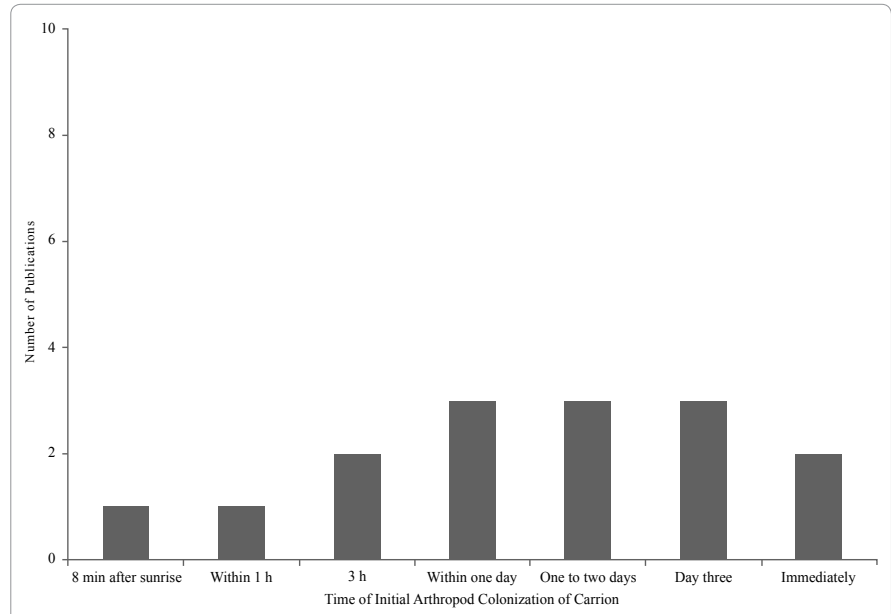

Figure 13: Summary of time of initial arthropod colonization of carrion after placement in the field recorded for past arthropod succession studies aimed at use in forensic entomology.

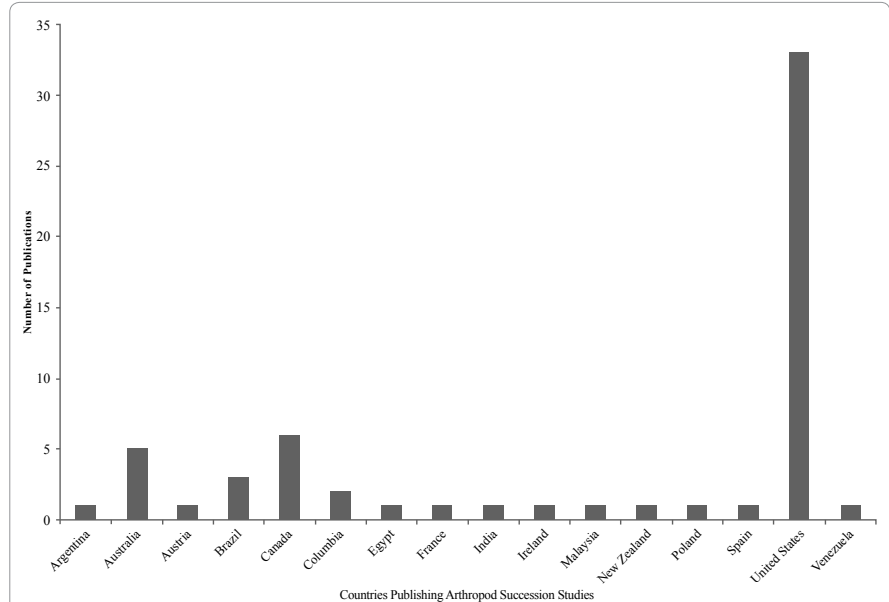

Figure 14: Summary of countries where past arthropod succession studies aimed at use in forensic entomology. countries, in descending order, were the United States (18\%), France (13\%), Italy (6\%), Australia (6\%), Germany (3\%), and Canada (3\%). Based on results from 2009, those values shifted to the United States (9\%), Australia (8\%), France (5\%), Germany (4\%), Italy (2\%), and Canada (2\%) (Tomberlin, unpubl. data). Within the United States from 1999 through 2003, research had been conducted in approximately 18 states including the District of Columbia. Consequently, many regions of the United States are still in need of baseline data regarding arthropod succession on carrion. What this means is that forensic entomologists are often applying data from one region to another with the hope that they are similar and allow for accurate PMI estimates to be made, something that could prove difficult to defend in a court of law. Future studies should record the location type (i.e., field or forest), shade cover, and plant diversity. Recording the latitude and longitude coordinates would be specific and allow the exact location of such sites to be determined in the future if needed.

These analyses indicate a tremendous amount of diversity in forensic-related succession studies around the world. However, the number of studies examining the succession of arthropods on carrion is limited. Furthermore, the lack of information regarding actual time of death and placement of the remains in a natural setting limits our ability to determine delays in colonization pattern. To exacerbate this issue, information related to time of initial arthropod contact and colonization was limited. Approximately $43 \%$ of the articles indicated some period of initial insect contact with the remains. Time intervals were highly variable demonstrating the tremendous amount of variation that may exist for such an event. Some intervals included $30 \mathrm{~s}$ [78], five minutes [27], three hours [73], one day [88], and within one to two days [83].

Some abiotic variables, such as wind, rain, cold weather, and environmental factors (i.e. water or soil) are known to delay colonization. However, the variation in delayed contact within a single ecosystem, much less within or between countries, is not known. Another major issue was the reliance on qualitative terms to describe the time of insect arrival at a carrion source $[16,17,20,41,50,79,89]$ which prevents accurate assessments and comparisons of previous studies as the definition of these terms is dependent on the researcher employing them.

The same trend observed for time of initial arthropod contact with remains was also prevalent when describing initial arthropod colonization. Some studies used specific measures, such as within one hour [19], within three hours [23], and three days after placement [90]. Time of colonization is a vital observation for describing the ecological processes occurring and its use in forensic entomological literature when estimating a portion of the PIA, and thus the PMI. Furthermore, these data can be used to validate published developmental data sets for a given location.

\section{Period of Study}

Our review of the literature indicated that decomposition studies have been conducted throughout the calendar year. As expected, a majority of the studies occurred during the warmer months of the year; however, arthropod colonization and succession during the cooler months have been examined to a lesser extent (Figure 15). But, if one were to step back and examine the total number of studies examining decomposition ecology as it relates to arthropod succession and location, we are just now beginning to understand the variations 
Citation: Tomberlin JK, Byrd JH, Wallace JR, Benbow ME (2012) Assessment of Decomposition Studies Indicates Need for Standardized and Repeatable Research Methods in Forensic Entomology. J Forensic Res 3:147. doi:10.4172/2157-7145.1000147

Page 8 of 10

surrounding arthropod diversity and succession on carrion. While some would view this as a hurdle, we view it as an opportunity.

\section{Statistical Evaluation}

Bear and deer carcass invertebrate communities presented the greatest number of arthropod taxa when compared to other carcass model types (Figure 16) [49]; however, there was no significant difference among carcass types which could be due to low replicates (Figure 7) for each animal type being used in the study. Similarly, there were no significant differences in taxa richness among carcass size classes, but those between $30-40 \mathrm{~kg}$ and $>50 \mathrm{~kg}$ harbored about 10 more taxa on average compared to the other size classes. Lastly, among previous studies examined, there was not a significant linear relationship with mean carcass mass and taxa richness indicating a large amount of variation both within and between studies of vertebrate carcass decomposition. These results, collectively, indicate the large degree of variation of invertebrate communities associated with vertebrate decomposition.

\section{Conclusion}

We recognize our study is not an exhaustive review of forensic entomology literature examining arthropod succession on carrion; however, our review represented the predominate literature related to forensic entomology research from a searchable database supplemented by older literature from four active researchers in the field. This review identified important criteria necessary for future replication of studies that are commonly, or not commonly, recorded in many cases. It also

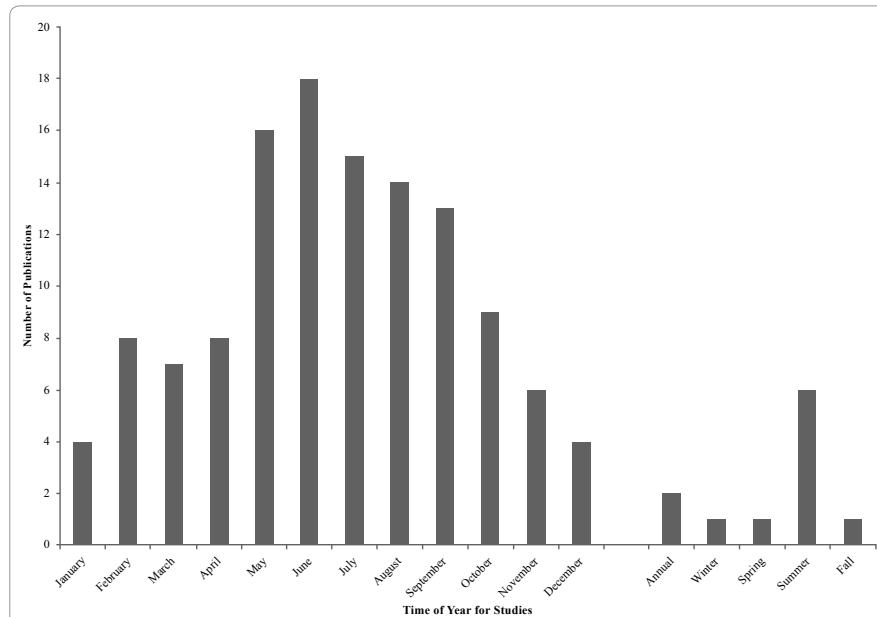

Figure 15: Summary of temporal period when past arthropod succession studies aimed at use in forensic entomology were conducted.

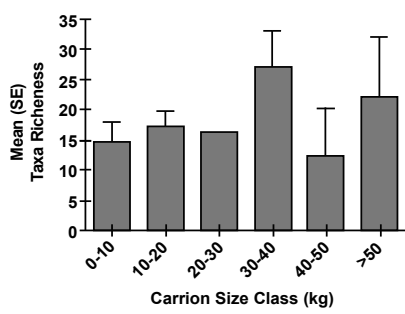

Figure 16: Mean (SE) invertebrate taxa richness by carcass mass category (in $10 \mathrm{~kg}$ intervals) reported from the papers reviewed and given in Figure 1 that reported carcass mass. The mean and SE were generated with paper as the replicate. demonstrated that current studies represent a patchwork of necessary data for more in depth comparisons of studies across ecosystems or for pooling data for more far reaching conclusions regarding variability in decomposition of carrion by arthropods.

We suggest that future research examining arthropod succession on decomposing remains include the following information; 1) animal model, 2) time of actual death, 3) euthanasia method, 4) storage method, 5) storage time, 6) time from removal from storage to placement in the field, 7) time of day remains placed in the field, 8) catalog of arthropods associated with remains over time 9) time of initial insect contact, 10) time of initial colonization (i.e. arthropod offspring located on the remains), 11) study site, 12) replicate information, and 13) months of study. By doing so, appropriate meta-analytical techniques could elucidate a better understanding of the variation that may exist in natural systems. Accordingly, an understanding of such variation could allow for better predictions of the post-colonization interval and potentially the amount of time between the moment of death and insect colonization. In the end, understanding this variation will lead forensic entomologists closer to providing estimates of a true PMI. Furthermore, by understanding the variation and potential error rate associated with the estimates provided by forensic entomologists, the science becomes more in line with the basic sciences meeting the recommendations provided by the National Research Council [12] and the Daubert Standard which govern our courtrooms.

\section{Acknowledgements}

The motivation for this research was not to criticize past research but to develop a standard operating procedure for collecting valuable data typically overlooked in decomposition research. Accounting for such information could lead to future meta-analyses that provides a better understanding of the decomposition process and potentially lead to increasing accuracy with predicting death of an individual based on entomological evidence.

\section{References}

1. Hall RD, Huntington TE (2010) Introduction: Perceptions and Status of Forensic Entomology. In Forensic Entomology: The Utility of Arthropods in Legal Investigations. J.H. Byrd and J. L. Casterner (eds.). CRC Press, Boca Raton, FL.

2. Catts EP, Haskell NH (1990) Entomology \& Death : A Procedural Guide. Joyce's Print Shop, Inc., Clemson, S.C.

3. Haskell NH (2007) Insect evidence distribution: tabulation of primary indicator species, the life stage, and the season of year used in final analysis from 100 random North American cases, pp. 220, American Academy of Forensic Sciences. American Academy of Forensic Sciences, San Antonio, Texas.

4. Byrd J, Castner J (2010) Forensic Entomology: The Utility of Arthropods in Legal Investigations. CRC Press, Boca Raton, FL.

5. Tsokos M, Villet MH, Amendt J (2011) Advances in Entomological Methods for Death Time Estimation. In: Forensic Pathology Reviews. E. E. E. Turk (ed.). Humana Press.

6. Amendt J, Campobasso CP, Gaudry E, Reiter C, LeBlanc HN, et al. (2007) Best practice in forensic entomology --standards and guidelines. Int $\mathrm{J}$ Legal Med 121: 90-104.

7. VanLaerhoven SL (2008) Blind validation of postmortem interval estimates using developmental rates of blow flies. Forensic Sci Int 180: 76-80.

8. Tomberlin JK, Benbow ME, Tarone AM, Mohr RM (2011) Basic research in evolution and ecology enhances forensics. Trends Ecol Evol 26: 53-55.

9. Tomberlin JK, Mohr R, Benbow ME, Tarone AM, VanLaerhoven SL (2011) A roadmap for bridging basic and applied research in forensic entomology. Annu Rev Entomol 56: 401-421.

10. Tarone AM, Foran DR (2011) Gene expression during blow fly development: improving the precision of age estimates in forensic entomology. J Forensic Sci 56: S112-S122. 
Citation: Tomberlin JK, Byrd JH, Wallace JR, Benbow ME (2012) Assessment of Decomposition Studies Indicates Need for Standardized and Repeatable Research Methods in Forensic Entomology. J Forensic Res 3:147. doi:10.4172/2157-7145.1000147

11. Tarone AM, Picard CJ, Spiegelman C, Foran DR (2011) Population and temperature effects on Lucilia sericata (Diptera: Calliphoridae) body size and minimum development time. J Med Entomol 48: 1062-1068.

12. National Research Council (U.S.). Committee on Identifying the Needs of the Forensic Science Community; Committee on Science, T., and Law Policy and Global Affairs; Committee on Applied and Theoretical Statistics Division on Engineering and Physical Sciences. 2009. Strengthening Forensic Science in the United States: A Path Forward. The National Academic Press, Washington, D.C.

13. Arnaldos MI, Romera E, Presa JJ, Luna A, Garcia MD (2004) Studies on seasonal arthropod succession on carrion in the southeastern Iberian Peninsula. Int J Legal Med 118: 197-205.

14. Blackith RE, Blackith RM (1990) Insect infestations of small corpses. J Nat Hist 24: 699-709.

15. O'Flynn MA (1983) The succession and rate of development of blowflies in carrion in southern Queensland and the application of these data to forensic entomology. J Aust Entomol Soc 22: 137-148.

16. Early M, Goff ML (1986) Arthropod succession patterns in exposed carrion on the island of O'ahu, Hawaiian Islands, USA. J Med Entomol 23: 520-531.

17. Lee HL, Marzuki T (1993) Preliminary observation of arthropods on carrion and its application to forensic entomology in Malaysia. Trop Biomed 10: 5-8.

18. Shean BS, Messinger L, Papworht M (1993) Observations of differential decomposition on sun exposed $\mathrm{v}$. shaded pig carrion in coastal Washington State. J Forensic Sci 38: 938-949.

19. Anderson GS, VanLaerhoven SL (1996) Initial Studies on Insect Succession on Carrion in Southwestern British Columbia. J Forensic Sci 41: 617-625.

20. Richards EN, Goff ML (1997) Arthropod succession on exposed carrion in three contrasting tropical habitats on Hawaii Island, Hawaii. J Med Entomol 34: 328339 .

21. Carvalho LM, Thyssen PJ, Linhares AX, Palhares FA (2000) A checklist of arthropods associated with pig carrion and human corpses in southeastern brazil. Mem Inst Oswaldo Cruz 95: 135-138.

22. Centeno N, Maldonado M, Oliva A (2002) Seasonal patterns of arthropods occurring on sheltered and unsheltered pig carcasses in Buenos Aires Province (Argentina). Forensic Sci Int 126: 63-70.

23. Grassberger M, Frank (2004) Initial study of arthropod succession on pig carrion in a central European urban habitat. J Med Entomol 41: 511-523.

24. Michaud JP, Moreau G (2009) Predicting the visitation of carcasses by carrionrelated insects under different rates of degree-day accumulation. Forensic Sci Int 185: 78-83.

25. Zurawski KN, Benbow ME, Miller JR, Merritt RW (2009) Examination of nocturnal blow fly (Diptera: Calliphoridae) oviposition on pig carcasses in midMichigan. J Med Entomol 46: 671-679.

26. Schoenly KG, Haskell NH, Hall RD, Gbur JR (2007) Comparative performance and complementarity of four sampling methods and arthropod preference tests from human and porcine remains at the Forensic Anthropology Center in Knoxville, Tennessee. J Med Entomol 44: 881-894.

27. Hewadikaram KA, Goff ML (1991) Effect of carcass size on rate of decomposition and arthropod succession patterns. Am J Forensic Med Pathol 12: 235-240.

28. Tantawi TI, eL-Kady EM, Greenberg B, El-Ghaffar HA (1996)Arthropod succession on exposed rabbit carrion in Alexandria, Egypt. J Med Entomol 33: 566-580.

29. Moura MO, de Carvalho CJ, Monteiro-Filho EL (1997) A preliminary analysis of insects of medico-legal importance in Curitiba, State of Paraná. Mem Inst Oswaldo Cruz 92: 269-274.

30. Bourel B, Martin-Bouyer L, Hedouin V, Cailliez JC, Derout D, et al. (1999) Necrophilous insect succession on rabbit carrion in sand dune habitats in northern France. J Med Entomol 36: 420-425.

31. De Jong GD, Chadwick JW (1999) Decomposition and arthropod succession on exposed rabbit carrion during summer at high altitudes in Colorado, USA. J Med Entomol 36: 833-845.
32. Bharti M, Singh D (2003) Insect faunal succession on decaying rabbit carcasses in Punjab, India. J Forensic Sci 48: 1133-43.

33. Keiper JB, Chapman EG, Foote BA (1997) Midge larvae (Diptera: Chironomidae) as indicators of postmortem submersion interval of carcasses in a woodland stream: a preliminary report. J Forensic Sci 42: 1074-1079.

34. Tomberlin JK, Adler PH (1998) Seasonal colonization and decomposition of rat carrion in water and on land in an open field in South Carolina. J Med Entomol 35: 704-709.

35. De Jong GD, Hoback WW (2006) Effect of investigator disturbance in experimental forensic entomology: succession and community composition. Med Vet Entomol 20: 248-258.

36. Velasquez $Y$ (2008) A checklist of arthropods associated with rat carrion in a montane locality of northern Venezuela. Forensic Sci Int 174: 68-70.

37. Srivastava DS, Cardinale BJ, Downing AL, Duffy JE, Jouseau C, et al. (2009) Diversity has stronger top-down than bottom-up effects on decomposition. Ecology 90: 1073-1083.

38. Watson EJ, Carlton CE (2003) Spring succession of necrophilous insects on wildlife carcasses in Louisiana. J Med Entomol 40: 338-347.

39. Clark K, Evans L, Wall R (2006) Growth rates of the blowfly, Lucilia sericata, on diferent body tissues. Forensic Sci Int 156:145-149.

40. Tarone AM, Foran DR (2006) Components of developmental plasticity in a Michigan population of Lucilia sericata (Diptera: Calliphoridae). J Med Entomol 43: 1023-1033.

41. Avila FW, Goff ML (1998) Arthropod succession patterns onto burnt carrion in two contrasting habitats in the Hawaiian Islands. J Forensic Sci 43: 581-586.

42. Shalaby OA, deCarvalho LM, Goff ML (2000) Comparison of patterns of decomposition in a hanging carcass and a carcass in contact with soil in a xerophytic habitat on the Island of Oahu, Hawaii. J Forensic Sci 45: 1267-1273.

43. Joy JE, Liette NL, Harrah HL (2006) Carrion fly (Diptera: Calliphoridae) larval colonization of sunlit and shaded pig carcasses in West Virginia, USA. Forensic Sci Int 164: 183-192.

44. Sharanowski BJ, Walker EG, Anderson GS (2008) Insect succession and decomposition patterns on shaded and sunlit carrion in Saskatchewan in three different seasons. Forensic Sci Int 179: 219-240.

45. Payne JA (1965) A summer carrion study of the baby pig Sus scrofa Linnaeus Ecology 46: 592-602.

46. Joy JE, Herrell ML, Rogers PC (2002) Larval fly activity on sunlit versus shaded raccoon carrion in southwestern West Virginia with special reference to the black blowfly (Diptera: Calliphoridae). J Med Entomol 39: 392-397.

47. Wolff M, Uribe A, Ortiz A, Duque P (2001) A preliminary study of forensic entomology in Medellin, Colombia. Forensic Sci Int 120: 53-59.

48. Tabor KL, Brewster CC, Fell RD (2004) Analysis of the successional patterns of insects on carrion in southwest Virginia. J Med Entomol 41: 785-795.

49. Watson EJ, Carlton CE, (2005) Insect succession and decomposition of wildlife carcasses during fall and winter in Louisiana. J Med Entomol 42: 193-203.

50. Martinez E, Duque P, Wolff M (2007) Succession pattern of carrion-feeding insects in Paramo, Colombia. Forensic Sci Int 166: 182-189.

51. Payne JA (1965) A Summer Carrion Study of the Baby Pig Sus scrofa Linnaeus Department of Entomology. 46: 592-602.

52. Archer MS (2004) Rainfall and temperature effects on the decomposition rate of exposed neonatal remains. Sci Justice 44: 35-41.

53. Davis JB, Goff ML (2000) Decomposition patterns in terrestrial and intertida habitats on Oahu Island and Coconut Island, Hawaii. J Forensic Sci 45: 836842.

54. Anderson GS, Hobischak NR (2004) Decomposition of carrion in the marine environment in British Columbia, Canada. Int J Legal Med 118: 206-209.

55. Anderson GS (2005) Effects of arson on forensic entomology evidence. Can Soc. Forensic Sci. J. 38: 49-67.

56. Nelder MP, McCreadie JW, Major CS (2009) Blow Flies Visiting Decaying Alligators: Is Succession Synchronous or Asynchronous? Psyche: 1-7. 
Citation: Tomberlin JK, Byrd JH, Wallace JR, Benbow ME (2012) Assessment of Decomposition Studies Indicates Need for Standardized and Repeatable Research Methods in Forensic Entomology. J Forensic Res 3:147. doi:10.4172/2157-7145.1000147

Page 10 of 10

57. VanLaerhoven SL, Anderson GS (1999) Insect succession on buried carrion in two biogeoclimatic zones of British Columbia. J Forensic Sci 44: 32-43.

58. Tessmer JW, Meek CL, Wright VL (1995) Circadian patterns of oviposition by necrophilous flies (Diptera: Calliphoridae) in southern Louisiana. Southwest Entomol 20: 439-445.

59. Patrican LA, Vaidyanathan R (1995) Arthropod succession in rats euthanized with carbon dioxide and sodium pentobarbital. J New York Entomol Soc 103: 197-207.

60. Micozzi MS (1986) Experimental study of postmortem change under field conditions: effects of freezing, thawing, and mechanical injury. J Forensic Sci 31: 953-961.

61. Reed JHB (1958) A Study of Dog Carcass Communities in Tennessee With Special Reference to the Insects. American Midland Naturalist 59: 213-245.

62. Tullis K, Goff ML (1987) Arthropod succession in exposed carrion in a tropoical rainforest on O'ahu Island, Hawai'i. J Med Entomol 24: 332-339.

63. Archer MS, Elgar MA (2003) Yearly activity patterns in southern Victoria (Australia) of seasonally active carrion insects. Forensic Sci Int 132: 173-176.

64. Archer MS, Elgar MA (2003) Effects of decomposition on carcass attendance in a guild of carrion-breeding flies. Med Vet Entomol 17: 263-271.

65. Greenberg B (1990) Nocturnal oviposition behavior of blow flies (Diptera, Calliphoridae). J Med Entomol 27: 807-810.

66. Villet MH, Richards CS, Midgley JM (2010) Contemporary Precision, Bias and Accuracy of Minimum Post-Mortem Intervals Estimated Using Development of Carrion-Feeding Insects. Current Concepts in Forensic Entomology 109-137.

67. Villet MH (2011) African carrion ecosystems and their insect communities in relation to forensic entomology. Pest Technol 5: 1-15.

68. Spivak M, Conlon D, Bell WJ (1991) Wind guided landing and search behavior in flesh flies and blowflies exploiting a resource patch (Diptera: Sarcophagidae, Calliphoridae). Ann Entomol Soc Amer 84: 447-452.

69. Rosati JY, VanLaerhoven SL (2010) Colonization behavior of forensically important blow fly species implications for postmortem interval estimations American Academy of Forensic Sciences. Publication Printers Denver Colorado Seattle Washington 310-311.

70. Wells JD, Greenberg B (1992) Rates of predation by Chrysomya rufifacies (Macquart) on Cochliomyia macellaria (Fabr) (Diptera: Calliphoridae) in the laboratory effect of predator and prey development. Pan- Pacific Entomol 68: 12-14.

71. Byrd JH, Butler JF (1996) Effects of temperature on Cochliomyia macellaria (Diptera: Calliphoridae) development. J Med Entomol 33: 901-905.

72. Byrd JH, Butler JF (1997) Effects of temperature on Chrysomya rufifacies (Diptera:Calliphoridae) development. J Med Entomol 34: 353-358.

73. Greenberg B (1990a) Behavior of Postfeeding Larvae of Some Calliphoridae and a Muscid (Diptera). Ann Entomol Soc Amer 83: 1210-1214.

74. Singh D, Bharti M (2001) Further observations on the nocturnal oviposition behaviour of blow flies (Diptera: Calliphoridae). Forensic Sci Int 120: 124-126.

75. Baldridge RS, Wallace SG, Kirkpatrick R (2006) Investigation of nocturnal oviposition by necrophilous flies in central Texas. J Forensic Sci 51: 125-126.

76. Amendt J, Zehner R, Reckel F (2008) The nocturnal oviposition behaviour of blowflies (Diptera: Calliphoridae) in Central Europe and its forensic implications. Forensic Sci Int 175: 61-64.

77. Pritam HM, Jayaprakash PT (2009) Nocturnal ovivposition behavior of necrophagous dipterans in Kelantan Malaysia*. J Forensic Sci 54: 1135-1140.

78. Gruner SV, Slone DH, Capinera JL (2007) Forensically important Calliphoridae (Diptera) associated with pig carrion in rural north-central Florida. J Med Entomol 44: 509-515.

79. Archer MS (2003) Annual variation in arrival and departure times of carrion insects at carcasses: implications for succession studies in forensic entomology. Aust J Zool 51: 569-576.

80. Gomes L, Gomes G, Desuo IC (2009) A preliminary study of insect fauna on pig carcasses located in sugarcane in winter in southeastern Brazil. Med Vet Entomol 23: 155-159.

81. Payne JA (1967) A Comparative Ecological Study of Pig Carrion Decomposition and Animal Succession with Special Reference to the Insects Department of Entomology. Clemson University Clemson South Carolina 128.

82. Payne JA, King EW, Beinhart G (1968) Arthropod Succession and Decomposition of Buried Pigs. Nature 219: 1180-1181.

83. Payne JA, King EW (1972) Insect succession and decomposition of pig carcasses in water. J Georgia Entomol Soc 7: 153-162.

84. Watson EJ, Carlton CE (2005a) Succession of forensically significant carrion beetle larvae on larger carcasses (Coleoptera: Silphidae). Southwest Nat 4 335-346.

85. Grassberger M, Frank C (2003) Temperature related development of the parasitoid wasp Nasonia vitripennis as forensic indicator. Med Vet Entomol 17 257-262.

86. Goff ML (1989) Gamasid mites as potential indicators of postmortem interval Prog. Acarol 1: 433-450.

87. Tomberlin JK, Wallace J, Byrd JH (2004) The state of forensic entomology, American Academy of Forensic Sciences. American Academy of Forensic Sciences Dallas Texas 257-258.

88. Eberhardt TL, Elliot DA (2008) A preliminary investigation of insect colonisation and succession on remains in New Zealand. Forensic Sci Int 176: 217-223.

89. Carvalho LML, Thyssen PJ, Goff ML, Linhares AX (2004) Observations on the Succession Patterns of Necrophagous Insects on a Pig Carcass in an Urban Area of Southeastern Brazil. Aggrawal's Internet J. Forensic Med Toxicol 5 33-39.

90. Matuszewski S, Bajerlein D, Konwerski S, Szpila K (2008) An initial study of insect succession and carrion decomposition in various forest habitats of Central Europe. Forensic Sci Int 180: 61-69. 